\title{
„Is populism the future of European politics?" Eine Veranstaltung der Open Society Foundations am 7. November 2011 in Brüssel
}

Populismus ist zu einem Dauerthema in der europäischen Politik geworden, was längst auch in Brüssel, einem der Hauptfeindbilder der rechtspopulistischen Parteien, für Beunruhigung sorgt. Nach vier Konferenzen im Europäischen Parlament zur Gefahr des Populismus im ersten Halbjahr 2011, organisiert von den Grünen (unter anderem mit Cas Mud$\left.d e^{1}\right)$, den Liberalen, den Sozialisten und den Christdemokraten ${ }^{2}$ fand nun eine Veranstaltung der Open Society Foundations mit ihrem Initiator, dem milliardenschweren Finanzmarktspekulanten George Soros, am 7. November 2011 in Brüssel statt. Sie trug den Titel: „,We say what you think': Is populism the future of European politics?”

Im Kern der Tagung, an der unter anderem der namhafte britische Populismusforscher Paul Taggart ${ }^{3}$ teilnahm, stand neben der Endnote von Soros selbst die Vorstellung eines Forschungsprojekts über die Unterstützung rechtspopulistischer Parteien in den sozialen Medien, insbesondere via Facebook. ${ }^{4}$ Initiator war der britische Think Tank demos, der in Windeseile, methodisch durchaus fragwürdig, die Sichtweisen von über 10.000 Unterstützern von rechtspopulistischen Parteien zusammengetragen hatte. Für das von den Open Society Foundations finanzierte Projekt wurden neben demographischen Daten auch Informationen über die Wahrnehmung der gesellschaftlichen und individuellen Lage, politische Einstellungen und Aktivitäten sowie die Motivation zur Mitgliedschaft und zum Engagement in populistischen Parteien erhoben. Dabei ermittelten die Autoren der Studie die Anhängerschaft der Parteien über die „Fan-Mitgliedschaften“ der Facebook-Profile. Anschließend wurden auf den persönlichen Profilen der Parteisympathisanten Anzeigen geschaltet, die nach Anklicken auf eine Onlinebefragung weiterleiteten. Bei der Fallauswahl wurde die analytische Trennung zwischen Populismus und Extremismus ${ }^{5}$ aufgegeben, da Parteien wie die extremistische British National Party oder populistische Vertreter wie die Wahren Finnen oder die Dänische Volkspartei Eingang fanden. Auch die Unterstützer der deutschen marginalen Partei Die Freiheit ${ }^{6}$, der Versuch einer Kopie der Geert Wilders-Partei aus den Niederlanden, wurden in die Untersuchung einbezogen. Einmal mehr blieben die Vertreter aus Zentral- und Osteuropa unberücksichtigt, obwohl mehr als zwei Jahrzehnte verstrichen sind und die vergleichende Forschung längst konsolidierte Demokratien erkennt. Gleichwohl sind die Ergebnisse interessant und bedenkenswert: Unterstützer in den

1 Cas Mudde hat das bislang beste Überblickswerk unter Einschluss Osteuropas verfasst. Vgl. ders., Populist Radical Right Parties in Europe, Cambridge 2007.

2 Vgl. Florian Hartleb, Vier Konferenzen im Europäischen Parlament zur „neuen Gefahr des Populismus" am 30./31. März und 21. Juni 2011 in Brüssel, in: ZParl, 42. Jg. (2011), H. 2, S. 466 - 469.

3 Vgl. Paul Taggart, Populism, Buckingham 2000.

4 Vgl. Jamie Bartlett / Jonathan Birdwell / Mark Littler, „The rise of populism in Europe can be traced through online behaviour ..." - The New Face of Digital Populism, London 2011.

5 Vgl. Florian Hartleb, After their Establishment: Right-wing Populist Parties in Europe, Brüssel 2011.

6 Bei der Wahl zum Abgeordnetenhaus von Berlin 2011 erreichte die Partei mit Schwerpunkt auf Berlin magere 1,0 Prozent der Zweitstimmen und scheiterte somit an der Fünfprozenthürde. Die Piratenpartei, eine Protestpartei aus dem linksalternativen Spektrum, war hingegen erfolgreich und konnte ins Parlament einziehen. Erneut zeigt sich das Scheitern rechtspopulistischer Vertreter in Deutschland. 
immer wichtiger werdenden sozialen Netzwerken sind vornehmlich junge Männer, die aber entgegen dem Klischee der Modernisierungsverliererthese in der Regel eine Beschäftigung vorweisen können. Die EU sehen sie in höchstem Maße kritisch, vor allem aus der Sorge, nationale und kulturelle Identität zu verlieren. Für die persönliche Zukunft legen sie Optimismus an den Tag, für die Zukunft ihres jeweiligen Landes hingegen nicht. Dieser Befund passt zu den allgemeinen gesellschaftlichen Individualisierungstendenzen. Insgesamt sind die Ergebnisse also wenig bahnbrechend.

Schillernder Sprecher der Konferenz war Loz Kaye, Vertreter der britischen Piratenpartei. Er hob in einer Pro-und Contra-Diskussion um Soziale Medien die positiven Wirkungen hervor. Während die Vertreter der Populismusstudie vor den Gefahren warnten, sah Kaye die Chance einer weltweiten Vernetzung, gerade jetzt im Zuge der Occupy-Bewegung. Mit Blick auf das taktische Verhalten der Piratenparteien für die Europawahl 2014 gehe es dann auch nicht um die Schaffung einer wie auch immer gearteten europäischen Identität. In der weiteren Diskussion kam es zu einer stärkeren Differenzierung des Populismusbegriffs. Paul Taggart von der Universität Sussex betonte, dass Populismus nicht die Demokratie unterminiere, sondern Regularien der repräsentativen Demokratie und die Komplexität des europäischen Mehrebenensystems ins Visier nehme. Er wies auf die Heterogenität rechtspopulistischer Parteien und deren chamäleonartige Züge hin. Péter Krekó vom Budapester Political Capital Institute betonte die Schwierigkeiten des Sonderfalls Ungarn ${ }^{7}$, wo mit Fidesz und der rechtsextremistischen Jobbik gleich zwei Parteien eine Diskussion notwendig machen. Krekó stellte heraus, dass die mit einer satten Zweidrittelmehrheit ausgestattete Fidesz durch ihre klare Freund-Feind-Zuordnung und den auf Viktor Orbán ausgerichteten Parteiaufbau sicherlich nicht in das westliche Muster passe. Jobbik verfolge im Parlament einen Mäßigungskurs, um dem Vorwurf des Neofaschismus zu entgegnen.

Catherine Fieschi von britischen Think Tank Counterpoint zeigte auf, dass der Populismus bislang nicht sonderlich von den Austeritätsmaßnahmen und den Zeiten der Rezession profitiert habe. Eine Ursache mag darin zu suchen sein, dass die rechtspopulistischen Vertreter kaum ökonomische Rezepte präsentieren können und ihr Heil eher in nationaler Abschottung und Antikapitalismus als Neidpolitik gegen die Mächtigen suchen. Fieschi machte eher auf die allgemeinen Krisen der modernen europäischen Demokratien aufmerksam: Assimilationskrisen, die sich in der westeuropäischen Integrationsproblematik zeigten, Erwartungskrisen durch den Verlust des Wohlstandes als bittere Erkenntnis für die jüngere Generation sowie Partizipationskrisen, die gerade auch auf europäischer Ebene deutlich würden. Am Ende der Tagung kritisierte George Soros, geboren 1930, die Politik im europäischen Krisenmanagement. Er sehe, ohne dies näher zu begründen, mindestens zehn Jahre europäische Depression voraus. Die Populismusstudie fand in zahlreichen Medienberichten Resonanz. Künftig dürften soziale Medien in der Demokratie-, Einstellungs-, Parteien- und Populismusforschung an Aufmerksamkeit gewinnen. Dies gilt besonders für die Parteienforschung, die auf diese Weise Einstellungen von Sympathisanten ermitteln kann, die über die gängigen Parteimitgliederstudien hinausreichen.

Florian Hartleb

7 Vgl. Melani Barlai / Florian Hartleb, Ungarischer Populismus und Rechtsextremismus. Ein Plädoyer für die Einzelfallforschung, in: Südosteuropa Mitteilungen, 48. Jg. (2008), H. 4, S. 34 51; dies., Rechtsextremismus als Posttransformationsphänomen - der Fall Ungarn, in: Totalitarismus und Demokratie, 7. Jg. (2010), H. 1, S. $83-104$. 